\title{
MODELLING AND ECONOMETRIC FRONTIERS IN MARKET INTEGRATION AND PRICE TRANSMISSION ANALYSIS
}

\author{
Isaac Abunyuwah \\ Department of Agricultural Economics and Extension, University of Education, Winneba,College of Agriculture \\ Education, Mampong, Ashanti, Ghana. Email: iabunyuwah@hotmail.com
}

\begin{abstract}
The broadness and inherent non-linearities in the market integration concepts have resulted in diversities in modelling framework. We critically review the current frontier models of market integration and highlight their weaknesses within the framework of competitive equilibrium theory and arbitrage dynamics. While the methods developed based on the former theoretical framework provide deeper equilibrium notions of markets functionality and implied efficiency, the study reveals that unaccounted time dynamics from inter-market relations can result in erroneous market outcomes and loss of crucial policy information. The extents to which techniques currently applied in dynamic frame are limited by non-linear complexities imposed by transactions costs and switching equilibrium conditions are also demonstrated. Sample splitting technique is suggested to address higher level nonlinearities imposed by switching equilibrium conditions and transactions cost.
\end{abstract}

KEYWORDS: market integration, equilibrium competitiveness, non-linear models, tradability

\section{INTRODUCTION}

In market economies, stronger price mechanisms and competitive forces lead to optimal allocation of scarce resources and economic growth. The strength and effectiveness of the price mechanism however depends on demand and supply equilibrium conditions that govern the market structure. Thus to understand the functionality of markets to appropriately inform policy designs and implementations price transmission and market integration analysis have been resorted to. As noted by Baulch (1997), without integration of markets for instance, price signals will not be transmitted from supply deficit regions to surplus markets; prices will be more volatile; agricultural and food producers for instance will not specialise according to long-run comparative advantage, and gains from trade will not be realised.

Variety of empirical methods have been developed and adopted for studying price transmission and market integration processes (Fackler and Goodwin 2001; Meyer and Cramon-Taubadel 2004; Abdulai 2007; and Fackler and Tastan 2008 for comprehensive review). These econometric techniques have grown rapidly from simple bivariate correlation analysis of price series to increasingly diverse and sophisticated methods. Notable improvements have been made, especially in the time series domain, with the introduction of cointegration and error correction models (ECM) during the late 1980s and early 1990s. These innovations in particular distinguished non-spurious from spurious relationships between (commonly non-stationary) prices, and by providing deeper insights into the equilibrating dynamics, generally attributed to arbitrage, that underlie the former. However, market integration in its engulfing conceptual settings has been proved by studies in the last decade to be more complex than usually assumed. These researches have as a result demonstrated that there are pitfalls associated with the general time series and cointegration methods to the analysis of market integration (Baulch 1997; McNew \& Fackler 1997; and Barrett 2001). These shortfalls are results of the conceptually diverse conditions that define market integration, for which price dynamics, though of major component, contribute only a part.

Major criticisms to price transmission methods have been propelled by equilibrium conditions that tradability concept (trade flow data in particular) and transfer cost data incorporate into market integration process. Cointegration and error correction modelling techniques which ignore these data; and also assume linear relationships between market prices tend to violate consistent market integration condition of discontinuities in trade, implied by spatial arbitrage conditions. Similarly, the nature of price formation in multi-market systems and trade flow reversals can lead to price series that are not cointegrated even though the markets in question are integrated. Consequently, as noted by Baulch (1997), markets that are well functioning are often diagnosed as 
exhibiting incomplete and /or lagged price adjustments. These insights have spurred applied economists to further refine the empirical methods that they use to analyse price transmission and market integration. Two major strands have emerged; the extension of vector ECM to threshold and other switching models (Goodwin and Piggot 2001, Sephton 2003, Meyer 2004, Serra et al. 2005 and Brümmer et al. 2005); and the parity bound models (PBM) and extensions (Baulch 1997, Barrett and Li 2002, Park et al. 2002 and Negassa et al. 2004) which use mixture distribution models that directly incorporate transfer and trade flow data (binary). The PBM techniques and the associated literature (Baulch, 1997 and Barrett \& Li, 2002 in particular) have helped to understand the relationship between market integration, price transmission and efficiency much better as they reflect the nature of markets inter-relationships or price transmission processes within arbitrage, spatial equilibrium and tradability concepts of market theory.

While major methodological progress has been achieved over the years in the measurement and testing of price transmission and market integration, these techniques tend to address an element or set of elements that define market integration (MI) as a concept. However these studies do not address the implications of market data complexity on MI and price transmission conclusions they arrive at. The extent to which these methods are limited by what level of data complexity and equilibrium conditions assumed have not been comprehensively investigated. This article fills this gap by providing comprehensive review of the two main methodological frontiers of MI analysis within competitive equilibria conditions and tradability concepts and demonstrates how they affect market integration conclusions when present but are ignored. We also suggest modelling framework to address higher levels of non-linearity.

Review of Major Market Integration Tools

Economic change and market policy dynamics have fundamentally altered the structure and performance of many commodity markets and their price formation processes. In market equilibrium theory, as demonstrated by Baulch (1997) and Barrett and Li (2002) based on Enke-Samuelson-Takayama-Judge (ESTJ) spatial equilibrium theory (Enke 1951; Samuelson 1952; Takayama and Judge 1971), three main market equilibrium conditions can be identified in general terms.

Thus, from spatial competitive equilibrium condition two market conditions follow;

$$
\begin{aligned}
& E\left\{P_{A t}\right\}=P_{B t}+\tau_{A B t} \\
& E\left\{P_{A t}\right\}<P_{B t}+\tau_{A B t}
\end{aligned}
$$

Where $\mathrm{E}$ is the expectation operator, $P_{A t}$ and $P_{B t}$ are prices in market $\mathrm{A}$ and $\mathrm{B}$ respectively in time $\mathrm{t}$, and $\tau_{A B t}$ is the transactions cost involved in trading from market B to A in time t. From the theory, if we take $P_{B t}$ and $\tau_{A B t}$ as given, then $P_{A t}$ is expected to be at least equal to $P_{B t}$ since in this setting, market A is importing from B. From (2.02) the negative expected profit to arbitrage means disincentive to trade. Hence this is consistent with spatial competitive equilibrium with non-trading activities (segmented competitive equilibrium), since in such cases there might be so high transfer costs that arbitrage is unprofitable in expectation (Samuelson 1952) for rational arbitrageurs to conduct trade. That is, if trade occurs and is unrestricted, the marginal trader earns zero profits and (2.01) prevails. Under this situation, prices in the two markets co-move perfectly. However, when some sort of trade restrictions exists, a third equilibrium condition holds:

$$
E\left\{P_{A t}\right\}>P_{B t}+\tau_{A B t}
$$

In (2.03) there exist positive expected returns to inter-market trade, signaling foregone arbitrage opportunities (Fackler and Goodwin, 2001). Here markets are characterized by imperfectly competitive equilibrium in which positive marginal profits to arbitrage are unexploited due, for example, to oligopsonistic or oligopolistic behaviuor or to binding quantitative restrictions on trade (e.g., quotas). The theory, in effect implies that in the long run markets may be characterised by switching equilibria (multiple competitive equilibria in time space); (perfect) co-movement of prices under equation (2.01) or imperfect competitive equilibrium without market efficiency as in equations (2.02) or (2.03). 
To observe any of the three equilibrium conditions at time $t$, depends on restrictions on arbitrage forces to clear the markets given the prevailing transactions $\operatorname{cost}^{1}$ (TC). In market analysis in general, it is difficult to establish a priori whether one of the three equilibrium structures prevails throughout the assessment period or two or all three conditions alternate in stochastic manner in the equilibrating process. With assumptions, guided by theoretical market concepts, many researchers have resorted to either price-based time series methods in linear or non-linear set up with the implicit notion that prices dynamics reflect market equilibria; or regime switching methods in static representation (parity bound models -PBM) that utilise more than price data in stochastically alternating equilibrium representation. We review these two major specific tools below.

Price Transmission Econometrics

Price transmission methods have dominated the MI literature over the years. This can be explained by the fact that their dynamic representations provide useful information on strengths and degree of adjustments of the inter-markets relationship. Again all market data are rarely available and in the form required. The application of price transmission tools are founded on the assumption of co-movement of two market prices in at least the long-run; and the richness and availability of price series vis-à-vis others.

As noted above, this strand of measures has revolved through many innovations; from the classical price correlation/bivariate regression through cointegration analysis and its recent extended versions. For instance Meyer (2004) applies Hansen and Seo's (2002) threshold vector form of the error correction model to infer transaction cost component in market integration analysis while van Campenhout (2007) relaxes the constant transactions cost component implied by threshold models (see also Buyst et al. 2006). Others make use of innovation accounting and a variant of principal component analysis to directly measure market integration in same cointegration framework. Von Cramon-Taubadel (1998), Ashe et al. (1999), Abdulai (2000, 2002 and 2007) and Balcombe and Morisson (2002) provide general developments in price transmission and cointegration applications. The history of studies on price dynamics in market analysis in general has long-lived, perhaps from the concept of market equilibrium in the wider spectrum of market efficiency analysis. In commodity markets, Farrell's (1952) empirical investigation on irreversible demand functions; and Lele (1967), Granger and Elliot (1967) and Tweeten and Quance (1969) price-based markets studies can be considered as some of the earliest efforts to employing price transmission econometrics in market integration analysis. We present the TAR models as the main current MI methodological frontier of the price transmission econometrics tools and demonstrate its strengths and weaknesses as implied by the ESTJ equilibrium theory.

Threshold autoregression models

From spatial market perspective and transaction costs constraints, it has become clear that many of the price adjustment processes follow nonlinear patterns (Goodwin \& Piggott 2001; Azzam 1999 and Baulch 1997). A TAR model occurs when the size of the lagged price differentials or equilibrium shocks lead to different degrees in the adjustment process in a regime fashion. In this case the adjustment parameter, $\rho$, varies according to whether the shock, $u_{t}$, is bigger or smaller than certain threshold values. A three-regime TAR can be represented as:

$$
\Delta R_{t}= \begin{cases}\rho_{1} R_{t-1}+u_{t 1} & \text { if }-\infty<R_{t-1} \leq \tau_{1} \\ \rho_{0} R_{t-1}+u_{t 2} & \text { if } \tau_{1}<R_{t-1} \leq \tau_{2} \\ \rho_{2} R_{t-1}+u_{t 3} & \text { if } \tau_{2}<R_{t-1}<+\infty\end{cases}
$$

where $\tau_{1}$ and $\tau_{2}$ are the threshold parameters. The above formulation (2.04) can be implemented following threshold tests by Balke \& Fomby (1997), Tsay (1989), Goodwin \& Holt (1999) and Goodwin \& Piggott (2001). Many extensions of (2.04) have emerged in the last decade. Meyer (2004) applies a variant of Hansen and Seo's (2002) two regime threshold cointegration in vector error correction model (VECM) to infer transactions cost component in a stylised symmetric representation as in (2.05) below.

\footnotetext{
${ }^{1}$ Transactions cost here implies the cost of trading between the two markets (includes transfer cost)
} 


$$
\Delta P_{t}= \begin{cases}\alpha_{1}+\beta_{1,0} P_{t-1}+\sum_{j=1}^{K}\left(\phi_{1, j} \Delta P_{t-j+1}\right)+e_{t} & \text { if } \mathrm{z}_{\mathrm{t}}<\tau_{1} \\ \alpha_{2}+\beta_{2,0} P_{t-1}+\sum_{j=1}^{K}\left(\phi_{2, j} \Delta P_{t-j+1}\right)+e_{t} & \text { if } \tau_{1} \leq z_{t} \leq \tau_{2} \\ \alpha_{3}+\beta_{3,0} P_{t-1}+\sum_{j=1}^{K}\left(\phi_{3, j} \Delta P_{t-j+1}\right)+e_{t} & \text { if } z_{t}>\tau_{2} .\end{cases}
$$

With some regularity assumptions, van Campenhout (2007) restricts the adjustment parameter and include time trend in the threshold parameter in a symmetric TAR model. Serra et al. (2005) have directly extended the classical TAR model to analyse MI by applying nonparametric techniques. Balcombe et al. (2007), attempt to generalise the traditional TAR formulation to directly test for band TAR (b-TAR) against equilibrium TAR (EqTAR) specification. The b-TAR models of price differentials, which are often used in the analyses of the law of one price and other arbitrage-based models in market integration analysis (see Obstfeld and Taylor 1997) can be deduced from standard threshold autoregressive (TAR) model in (2.04) as follows:

$$
\Delta R_{t}= \begin{cases}\rho_{1}\left(R_{t-1}-\tau_{1}\right)+u_{1} & \text { if } \infty>R_{t-1} \geq \tau_{1} \\ \rho_{0} R_{t-1}+u_{2} & \text { if } \tau_{1}>R_{t-1}>\tau_{2} \\ \rho_{1}\left(R_{t-1}+\tau_{2}\right)+u_{3} & \text { if } \tau_{2} \geq R_{t-1}>-\infty\end{cases}
$$

As Meyer and von Cramon (2004) note, threshold models can improve the specification in cases where transaction costs are present or the data generation process follows such a nonlinear pattern. But as in all regime-switching models the number of thresholds to be included and their tests in meaningful economic interpretation are still under investigation. The price transmission econometrics models through their rapid refinements with the advent of cointegration, error correction models and threshold extensions still do not provide a comprehensive framework for MI analysis, given the equilibrium conceptualization presented in equations (2.01) to (2.03) above. Nevertheless, it is probably the most useful tool in policy orientation as it provides a flexible structure where various market characteristics that define market integration and efficiency, namely; instantaneous and gradual price transmissions, transactions cost effects on adjustment processes, nonlinearity and asymmetry in the equilibrating processes can be specified and tested.

One of the well noted criticisms of the time series tools and cointegration is that it may be misleading in assessing MI if for example; prices in spatially separated markets have a common stochastic trend reflecting say, inflation. In this case the cointegration parameter will be equal to one reflecting a proportionality of unity or a common global shock, by implying that price transmission is complete. It has also been raised that price transmission testing framework does not identify the factors that affect market integration and price transmission, whether the dynamics are shaped by say transaction costs, policy intervention that insulates the domestic markets, trade quota or by the degree of market power exerted by agents in the supply chain. In effect, MI via price data or data without some market specific or an attempt to complement the results with some qualitative information on the major factors that may determine the extent of transmission may result in situation where one measures something different from what is intended.

Some authors have argued and proposed, particularly from spatial market analysis, that since PT econometrics usually mix market efficiency and competitive equilibrium analysis in inferring MI, models for MI analysis should be able to draw distinction between market integration and market efficiency that make use of more than price data. The PBM has been proposed in this respect, as it is claimed to be robust and overcomes these weaknesses of the conventional PT methods of testing for market integration. The next section presents the PBM along Baulch (1997), Park et al. (2002), Barrett and Li (2002) and Negassa et al. (2004) as a switching regime technique for MI analysis based on arbitrage conditions rather than prices dynamics. 
The Parity Bound Model (PBM)

The parity bound approach to MI analysis stems on efforts to discriminate between consistent arbitrage conditions and competitive market equilibrium that defines market efficiency. The development of the parity bounds model (PBM) represents an attempt to utilizing all available market data- prices, transfer costs and trade flows binary and volumes- possibly simultaneously, to describe markets along their long-run conceptual settings. Specifically, these models seek to draw distinction between spatial market efficiency and spatial market integration (Barrett and Li 2002). We present the basic model of Baulch (1997) which extends on those of Sexton et al. (1991) and Spiller and Wood (1988); and highlight on some recent refinements.

Let two markets prices, $P_{A}$ and $P_{B}$, represent markets $A$ and $B$ respectively. We also assume that they are located in different localities but deal with (common) tradable commodity. The markets can be described in terms of arbitrage possibilities that may exist between them at any point in time. From the spatial equilibrium theory as elaborated earlier, three arbitrage conditions may prevail at any given time; if trade occurs between the markets the prices will be equal or differentiated by transactions cost. In this case if transactions cost is denoted by $\tau$, then the following three conditions may exist, see equations (2.01)-(2.03) above; $P_{A t}=\tau_{A B t}+P_{B t}$, $P_{A t}<\tau_{A B t}+P_{B t}$ or $P_{A t}>\tau_{A B t}+P_{B t}$.

The transactions cost component is usually modeled as a random variable with time varying mean transfer costs, $\gamma$, and random component $v$ at time $t$. Classical PBM approach to MI analysis posits that in efficient and integrated markets, arbitrageurs ensure that no any arbitrage opportunity exists in the long run (i.e. rent to trade is zero- $\left.R_{t}=0\right)$. When the markets are characterised by non-zero rent to trade $\left(R_{t} \neq 0\right)$, then the markets are not perfectly integrated, although competitive spatial equilibrium and hence efficiency may prevail as discussed under spatial equilibrium theory above. From tradability concept however, observing trade between the markets is sufficient to imply market integration and therefore identifies the later cases in equations (2.02) and (2.03) with trade flow observations as weak form (imperfect) integration. Baulch (1997) specifies the PBM under the assumption of normal plus half-normal distribution along the stochastic production frontier applications. In this respect, the rent, $R_{t}$, series is assumed to be generated by one of the following process:

$$
R_{t}=\left\{\begin{array}{llll}
v_{t}+v_{t} & & R_{t}>0 & \text { Regime 2 } \\
v_{t} & \text { if } & R_{t}=0 & \text { Regime 1 } \\
v_{t}-v_{t} & & R_{t}<0 & \text { Regime 3 }
\end{array}\right.
$$

where $v_{t}$ is a one-sided positive half-normal error which is independent of $v_{t}$. This error structure denotes periods in which rent levels differ significantly from the expected normal zero profit levels. The $v_{t}$ error component describes perfect integration conditions where rent levels do not significantly differ from zero and as such are represented by a normally distributed error with mean $\alpha$ (Baulch 1997 uses zero mean) and variance $\sigma_{u}^{2}$. The $v_{t}$ is usually assumed symmetric around the transactions cost component. The $v_{t}$ 's effect under regime 3, implies how imbalance the two market forces are in the presence of relatively higher transactions cost; while on regime 2, it measures the extent to which rent exceeds transactions cost when the spatial arbitrage conditions are violated, the so-called failed arbitrage (Park et al. 2002).

If $f_{t}$ defines the probability function for equation (2.07) under the assumption of normal plus half-normal distribution, the three regimes can be specified as (2.08) with likelihood function (2.09); and (2.10 \& 2.11) if trade information is further utilised to distinguish between perfect and imperfect integration as in Barrett and $\mathrm{Li}$ (2002): 


$$
\begin{aligned}
& f_{t}^{1}=\frac{1}{\sigma_{v}} \phi\left[\frac{R_{t}-\alpha}{\sigma_{v}}\right] \\
& f_{t}^{2}=\left[\frac{2}{\left(\sigma_{u}^{2}+\sigma_{v}^{2}\right)^{1 / 2}}\right] \phi\left[\frac{R_{t}-\alpha}{\left(\sigma_{u}^{2}+\sigma_{v}^{2}\right)^{1 / 2}}\right] \times\left[1-\Phi\left[\frac{-\left(R_{t}-\alpha\right)^{\sigma_{u}} / \sigma_{v}}{\left(\sigma_{u}^{2}+\sigma_{v}^{2}\right)^{1 / 2}}\right]\right] \\
& f_{t}^{3}=\left[\frac{2}{\left(\sigma_{u}^{2}+\sigma_{v}^{2}\right)^{1 / 2}}\right] \phi\left[\frac{R_{t}-\alpha}{\left(\sigma_{u}^{2}+\sigma_{v}^{2}\right)^{1 / 2}}\right] \times\left[1-\Phi\left[\frac{\left(R_{t}-\alpha\right)^{\sigma_{u}} / \sigma_{v}}{\left(\sigma_{u}^{2}+\sigma_{v}^{2}\right)^{1 / 2}}\right]\right] \\
& L=\prod_{t=1}^{T}\left[\lambda_{1} f_{t}^{1}+\lambda_{2} f_{t}^{2}+\left(1-\lambda_{1}-\lambda_{2}\right) f_{t}^{3}\right] \\
& f_{A B t}^{1 T d}=f_{A B t}^{1 n T}=\frac{1}{\sigma_{v}} \phi\left[\frac{R_{A B t}-\alpha}{\sigma_{v}}\right] \\
& f_{A B t}^{2 T d}=f_{A B t}^{2 n T}=\left[\frac{2}{\left(\sigma_{u}^{2}+\sigma_{v}^{2}\right)^{1 / 2}}\right] \phi\left[\frac{R_{A B t}-\alpha}{\left(\sigma_{u}^{2}+\sigma_{v}^{2}\right)^{1 / 2}}\right] \times\left[1-\Phi\left[\frac{-\left(R_{A B t}-\alpha\right)^{\sigma_{u} / \sigma_{v}}}{\left(\sigma_{u}^{2}+\sigma_{v}^{2}\right)^{1 / 2}}\right]\right] \\
& f_{A B t}^{3 T d}=f_{A B t}^{3 n T}=\left[\frac{2}{\left(\sigma_{u}^{2}+\sigma_{v}^{2}\right)^{1 / 2}}\right] \phi\left[\frac{R_{A B t}-\alpha}{\left(\sigma_{u}^{2}+\sigma_{v}^{2}\right)^{1 / 2}}\right] \times\left[1-\Phi\left[\frac{\left(R_{A B t}-\alpha\right)^{\sigma_{u}} / \sigma_{v}}{\left(\sigma_{u}^{2}+\sigma_{v}^{2}\right)^{1 / 2}}\right]\right]
\end{aligned}
$$

In (2.10) where trade flow data is included in the estimation, six market conditions prevail. We use notations $A B t$ to imply direction specific rent and transactions $\operatorname{cost}^{2}$. In principle, the three equilibrium conditions as identified in (2.01 2.03)- when the marginal profit to arbitrage is equal to, greater or less than zero- with-trade $(T d)$ or without-trade $(n T)$, define the six possible states (regimes) which further reduce to four market conditions of interest as indicated in Barrett and $\mathrm{Li}$ (2002). The $\lambda_{k}$ are probabilities, describing the six regimes and the error parameters are defined by $\alpha, \sigma_{\mathrm{u}}^{2}$ and $\sigma_{\mathrm{v}}^{2}$. From equations (2.07) - (2.11), $\phi$ is the standard normal density function and $\Phi$ is the standard cumulative distribution function.

Market equilibrium theory is consistent with cases where rent $\left(R_{A B t}\right)$, is zero with or without trade, and where $R_{A B t}<0$ without trade. Impliedly, whether trade occurs or not with $R_{A B t}>0$ is inconsistent with market equilibrium. However, from the tradability and contestability concepts market integration holds whenever trade occurs and or the equilibrium condition is binding $\left(R_{A B t}=0\right)$. In effect, four of the six possible regimes define market integration. The tradability concept in this respect seems plausible since in practice one cannot observe all possible elements of transactions costs- such as subjective risk premia, discount rates or quasi-option value. Trade flow information can therefore offer indirect evidence on the effects of unobservable or omitted transactions costs (see Barrett and Li 2002), as well as lag price adjustments. The PBM in this context estimates

\footnotetext{
${ }^{2}$ Note that, at time $t$ arbitrage will dictate only one directional rent in a long run representation for economically tradable goods, unless classical multiple equilibrium conditions hold.
} 
the joint probability of the rent $\left(R_{A B t}\right)$ and trade $\left(T d_{A B}\right)$ in maximum likelihood estimation as specified under the distribution function (2.10) and (2.11) below with trade flow information. $A_{j i t}$ is an indicator variable that takes value one if trade is observed and zero otherwise.

$$
L=\prod_{t=1}^{T}\left(A_{j i t} \cdot\left[\lambda_{1} f_{j i t}^{1 T d}+\lambda_{3} f_{j i t}^{2 T d}+\lambda_{5} f_{j i t}^{3 T d}\right]+\left(1-A_{j i t}\right) \cdot\left[\lambda_{2} f_{j i t}^{1 n T}+\lambda_{4} f_{j i t}^{2 n T}+\lambda_{6} f_{j i t}^{3 n T}\right]\right)
$$

The regime probabilities can be estimated by maximising the extended likelihood (2.11), with logarithm of the likelihood function, subject to the constraints, $\lambda_{k} \geq 0 \forall k$ and $\sum_{\mathrm{k}} \lambda_{\mathrm{k}}=1$. Baulch's case assumes that $\alpha=0$ and a constant $A_{j i t}$, which implies that trade either always occurs or never at all; assumptions Barrett and $\mathrm{Li}$ (2002) consider strong. As noted by Park et al. (2002), the standard PBM as specified in (2.08), does not allow tracking of adjustment paths and the effects of say policy changes on the probabilities of different trade regimes. Trying to avoid identification problem in their specification, they defined policy regime-periods within which the parameters were assumed to be constant. Negassa et al. (2004) generalises that of Park et al. (2002) to reflect both instantaneous and gradual change in regime probabilities due to policy changes in studying the grain market of Ethiopia. Their idea can be seen as identifying structural changes in PT econometric systems. Extending the standard PBM in this direction they make provision for transition phase and re-formulate (2.09) as (2.12) below.

$$
L=\prod_{t=1}^{T}\left[\lambda_{1} f_{j i t}^{1}+\delta_{1} D_{t} f_{j i t}^{1}+\lambda_{2} f_{j i t}^{2}+\delta_{2} D_{t} f_{j i t}^{2}+\left(1-\lambda_{1}-\lambda_{2}-\delta_{1} D_{t}-\delta_{2} D_{t}\right) f_{j i t}^{3}\right]
$$

The $\delta_{k}$ in (2.12) measures the structural change in the probability parameter of being in regime $k$ due to the policy changes and $D_{t}$ is a transition-phase dummy variable, which characterizes the alternative time path of structural change in regime probabilities (see Ohtani and Katayama 1986; Moschini and Meilke 1989; Negassa et al. 2004; Negassa and Myers 2007).

Major challenges that one usually encounters in implementing PBM is how to get all data types in a form that is usually required. For instance the very data inputs that PBM claims to throw more light on the system dynamics than PTE are usually not available or in the form needed for comprehensive time series analysis. However, as an alternative, and as is usually the case where time series transactions cost data is not available, some authors estimate the transfer costs based on decomposition of the observed spatial price differentials (Park et al. 2002), even though, this may implicitly assume a time invariant transfer cost component. Others in effect, do the estimation of the transfer cost data either by using the marketing cost computed from surveys and adjusting for inflation (e.g., Baulch 1997) or inflating the time series transport cost data by a certain percentage to account for the unobserved components of transfer costs (Negassa et al. 2004 and references indicated).

In sum, the PBM improves on MI assessment as it marries the theoretical concepts of markets inter-relationships and market data. However, the PBM and its extensions also have some well-known weaknesses. The results are often sensitive to the distributional assumptions made, especially the half-normal distributions seem questionable if one could perceive the system as regime switching process governed by multiple equilibria mechanism as the ESTJ theory posits. Again, the constraints to accurately estimating the transfer and transaction costs might also bias the results (see Goodwin \& Piggott 2001). Moreover, the various assumptions usually imposed on the system to avoid identification problem may affect the estimated parameters (see van Campenhout 2007). Another important issue with PBM is that, it does not directly accommodate price or rent dynamics in the inter-market relationships. To avoid the danger of specification bias, lower frequency data are usually resorted to in PBM applications (see e.g. Park et al. 2002, Barrett and Li 2002).

Implications of non-linear market data complexity on MI conclusions

The above methodological overview of the two main frontiers of MI analysis shows that market integration is a broad concept and hence its definition can be vague or very restrictive depending on what one wants to measure. For instance tradability represented by physical trade flow is sufficient to imply MI from PBM perspective but without price transmission such approach can result in biased conclusions, overstating the crucial segmented 
states since tradability can also imply information flow between markets without physically observing trade. To illustrate this position assume that two markets are integrated over a given period of time, $t_{l}$ to $t_{n}$, but switches between perfect and imperfect integration phases. At the same time the adjustment processes are characterised by transactions costs based (TC-based) TAR effects as usually assumed under PBM applications. If tradability is implied by both physical trade and information flows and periods of imperfect integration do not always correspond to physical trade flow, which is very likely in lean seasons of many commodity markets at least in the developing markets and presence of market power, price transmission will occur though it might be incomplete. This is illustrated graphically in figure 1 below.

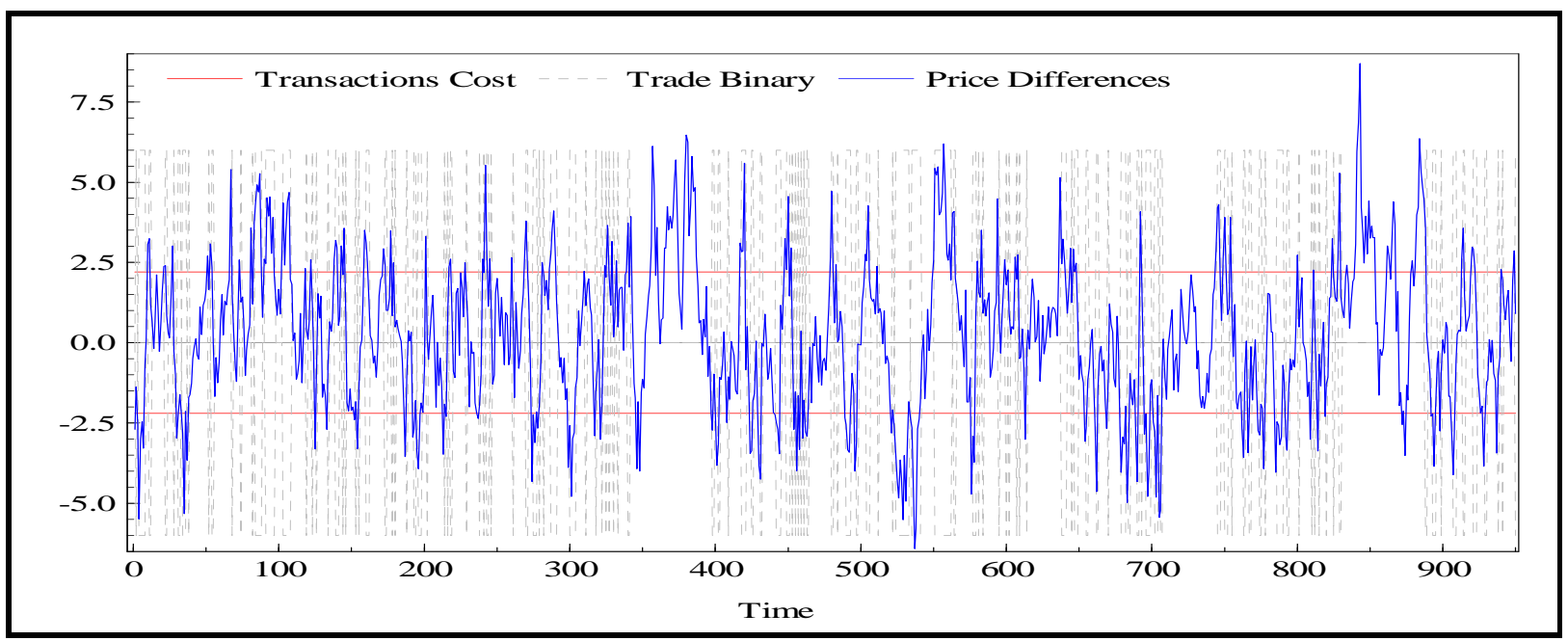

Figure 1: Band-TAR illustration within switching inter-market conditions

From figure 1, periods around (341-390 and 831-885) do not correspond to physical trade flow while the rent levels exceed zero at expectation but price transmission transpires. With this categorisation, if PBM is used these two episodes wrongly fall outside market integration regimes into segmented equilibrium / disequilibrium states as these rent levels are significantly different from zero at expectation. In sum, by inferring tradability only on physical trade flow implicitly carry the assumption that physical trade flow is necessarily associative with tradability once perfect competition/integration does not hold. This is very strict if the multiple equilibria implications of the ESTJ equilibrium representation are to be fully accommodated in MI analysis especially in time space; and as well, if information flow implications on tradability defined by Walrasian transfer and Pareto inefficiency are to be taken into account.

Again, since trade often occurs even when rent differ from TC, and the fact that in many inter-market trading, contracting and transportation lags push traders to respond to inter-market prices and rent variations before actual transactions are made, observed trade flow may not correspond to a given rent level and since such lags may not be constant as well, transient shocks may incorrectly be picked as imperfect or segmented conditions. Moreover due to the inherent outcome-based structure of the PBM notion and the fact that activities within the threshold band that do not correspond to trade do not violate MI or competitive equilibrium, even if markets have no relations but their price differentials fall within an expected or estimated parity bound $\left(R_{t}=0\right)$, the markets will be wrongly denoted as perfectly integrated markets (since conditions under equation (2.01) is satisfied). Thus while classical time series models fail when perfectly integrated and well functioning markets do not exhibit price co-movements (rent adjustments due to say TC constraints) over time, the static and outcome based measures in the opposite manner will incorrectly treat two economically separated markets periods that happen to have substantial time points of lower price differentials as perfectly integrated markets.

Dynamic adjustments in the market equilibrium process do not only contain rich information for explaining the extent and degree of MI but can further help distinguish MI and ME conditions that underpin outcome-based models. From the equilibrium representation however, it is worth noting that while price formation structures dwell heavily on demand and supply interactions, it is only under (perfect) competitive market equilibrium that one can both assume long-run measure of no-arbitrage and efficiency. In effect, price transmission analysis that do not accommodate all the possible underlying equilibrium conditions tend to address a particular form of MI 
Isaac Abunyuwah: Continental J. Agricultural Economics 6 (1): 28 - 39, 2012

and may be biased where other conditions hold. As demonstrated in Abunyuwah (2008), complete market integration conceptualization alter the threshold space with an additional layer of non-linear complication. In this respect the three- state b-TAR model would not produce estimates that a pure TC based threshold data generation process (DGP) will suggest.

These complications suggest that when a mixture of TAR and switching inter-market conditions ensue, threshold models may miss the true inter-markets dynamics that govern the system and produce biased parameter estimates. Depending on the nature of non-linear complexity that governs the DGP the estimated adjustment process and levels of threshold constraints derived from TAR specifications can be misrepresentation of the true equilibrating structure if switching inter-markets equilibrium conditions hold. For instance, to evaluate the presence of TAR, it is expected that the adjustment process in some periods is governed by threshold effects as a result of TC constraints where rho $(\rho)$ should not differ significantly from zero to reflect random walk nature of the price differentials within the threshold band while the remaining ones should indicate strong correction once threshold band is exceeded. However, such periods of swift adjustments tend to be blurred by the strong persistence that characterises segmented inter-markets phases that do not follow any threshold processes, obviously under-estimating these parameters since they are assumed constant outside threshold band.

The linkage between MI and competitive market equilibrium is important for meaningful MI analysis, especially with limited information on tradability and transactions costs. Ignoring the other, usually the later in the analysis of the former, can imply different welfare outcomes and in effect policy concerns. That is;

"In order for markets to fulfill the promise they offer for risk management, efficient distribution of production according to comparative advantage, clear transmission of policy signals, and maintenance of micro-level incentives to innovate, there should be neither segmented competitive equilibria nor effective trade quotas Given limited data, in particular a paucity of data on transactions costs and trade volumes, and the intrinsic limitations of existing empirical methods, economists still have only a fragile empirical foundation for reaching clear, strong judgements about spatial market integration as a guide for corporate or government policy"(Barrett, 2005).

Depending on the nature of trade policy environment, distortions that characterise the markets and transactions costs involved in conducting trade, price series may behave in various ways of relationships. Thus, while MI can be evaluated via any of the above two major methodological frame under specific assumptions of the market, each has a potential weakness when a complete conceptual foundation of MI theory is to be inferred. Each measurement tool depends on the specificity of the market under consideration and as such fails to distinctively address the relationship between the law of one price, competitive spatial market equilibrium and implied efficiency, nature of arbitrage dynamics; and market integration within each model frame.

Methodological areas for exploration

Though scanty, applications of Markov switching models in addressing non-linearities implied by rent and or adjustment levels (see Abunyuwah, 2008: Bruemmer et al. 2005; Kostov et al. 2004) in market integration analysis provide room for inferring arbitrage conditions (market outcomes) in dynamic framework. These models do not however, account directly for transactions cost effect on the adjustment processes and do not explicitly impose the three equilibria conditions as in the case of the PBM. Impliedly, while the later condition provides direct framework for testing for number of regimes in levels of rent present in the series to infer market equilibrium conditions that govern the system, the transactions costs constraints which appear in the form of random walk process in the TAR band creates mixture of strong persistence and adjustment phases within perfect integration regimes. This places constraints on the Markov switching models in effectively isolating the adjustment periods from the random walk phases (see Abunyuwah 2008 for comprehensive investigation).

To address non-linear complexities implied by transactions costs and switching inter-markets equilibria conditions van Campenhout (2009) and Abunyuwah (2008) have proposed an investigation into sample-splitting techniques along those developed by Hansen (2000) and in arranged autoregression modeling. That is, where TC component is accounted for or concentrated out, regime switching techniques that can accommodate regime shifts in the adjustments parameters and rent levels can be used to discriminate between segmented regimes and imperfect integration in the form of mean/intercept and or adjustment parameter shifts without directly using trade flow binary or volumes. 


\section{CONCLUSION}

Indeed growing advances in market integration and price transmission measurements have generated popular view that the traditional models for commodity markets integration analysis within a linear setting are inconsistent under many real world situations in explaining observed movements in market phenomena. The diversion to recent non-linear and regime switching versions indicate a direction to the domains of models with implicit assumption of multiple equilibria, since MI and ME are intrinsically interlinked. As implied by ESTJ spatial equilibrium theory, and the fact that many commodity markets and trade regions are characterised by changing policy schemes, technological innovations on transactions cost and their associated uncertainties on market decisions, it is quite appealing to suspect that many commodity markets would relate differently in particular periods of large transactions cost, more liberalized market schemes, policy uncertainties, in strategic planning phases in time and presence of market power. In applied economics in general, presence of such features make it difficult to explain aggregate long-run behaviuor using traditional linear models. Current nonlinear tools usually applied in MI analysis ignore effects of data complexity implied by such non-linear structures on their conclusions. This article has raised specific sources and nature of pitfalls implied by data complexities imposed by tradability, TC and competitive equilibrium conditions in both static and dynamic applications.

\section{REFERENCES}

Abdulai, A. (2000). Spatial price transmission and asymmetry in the Ghanaian maize market. Journal of Development Economics, 63: 327-349.

Abdulai, A. 2002. Using threshold cointegration to estimate asymmetric price transmission in the Swiss Pork market. Applied Economics 34(6), 679-687.

Abdulai, A. (2007). Spatial and Vertical price transmission in food staples market chains in Eastern and Southern Africa: What is the evidence? Paper presented at the FAO Trade and Markets Division Workshop on Staple Food Trade and Market Policy Options for Promoting Development in Eastern and Southern Africa, Rome, March 1-2, 2007.

Abunyuwah, I. (2008). Market Integration Analysis and Time-series Econometrics- Conceptual Insights from Markov-switching Models. SUB. University of Göttingen, Germany (PhD Dissertation).

Asche F., Bremnes H. and Wessels C. R. (1999). Product aggregation, market integration and relationships between price. An application to world salmon market. American Journal of Agricultural Economics, 81(4), $568-581$.

Azzam, A. M. (1999) Asymmetry and rigidity in farm-retail price transmission, American Journal of Agricultural Economics, 81, 525-33.

Balcombe, K. and J. Morrison. (2002). Commodity price transmission: A critical review of techniques and an application to selected export commodities. A study for the Food and Agricultural Organization (ESCR) of the United Nations, Rome, Italy.

Balcombe K., A. Bailey And J. Brooks (2007). Threshold effects in price transmission: the case of Brazilianwheat, maize, and soya prices. American Journal of Agricultural Economics 89(2), 308-323

Balke, N.S. and T.B. Fomby (1997). Threshold cointegration. International Economic Review. 38, 627-645.

Barrett, C. B. (2001). Measuring integration and efficiency in international agricultural markets. Review of Agricultural Economics, 23(1), 19-32.

Barrett, C.B. (2005). "Market integration": In The New Palgrave Dictionary of Economics, 2nd edition, ed. Lawrence E. Blume and Steven N. Durlauf, (London: Palgrave Macmillan).

Barrett, C. B., \& Li, J. R. (2002). Distinguishing between equilibrium and integration in spatial price analysis. American Journal of Agricultural Economics, 84(May 2002), 292-307. 
Baulch, B. (1997). Transfer costs, spatial arbitrage, and testing for food market integration. American Journal of Agricultural Economics, 79(May 1997), 477-487.

Brümmer, B., Cramon-Taubadel, S. and Zorya (2005). Wheat / flour price transmission and agricultural policies in Ukraine: a Markov-switching vector error correction approach. Working paper, Institute of Agricultural Economics, University of Goettingen, Goettingen. Germany.

Buyst, E., Dercon, S. and van Campenhout B. (2006). Road expansion and market integration in the Austrian Low Countries during the second half of the 18th century. In: Histoire et mesure, 21 (1), 185-220.

Enke, S. (1951). Equilibrium among spatially separated markets: solution by electrical analogue. Econometrica $19,40-7$.

Fackler, P. L., and Goodwin, B. K. (2001). Spatial price analysis. In B. L. Gardner, \& G. C. Rausser (Eds.), Handbook of Agricultural Economics (pp. 972-1024). Amsterdam:Elsevier Science.

Fackler, P. L and Tastan, H. (2008): Estimating the Degree of Market Integration. American Journal of Agricultural Economics: (90):1, pp: 69-85.

Farrell, M.J. (1952). Irreversible demand functions. Econometrica, 20, 171-186.

Goodwin, B.K., and Holt, M.T. (1999). Price transmission and asymmetric adjustment in the US beef sector. American Journal of Agricultural Economics, 81, 630-637.

Goodwin, B.K. and Piggott, N.E. (2001). Spatial market integration in the presence of threshold effects. American Journal of Agricultural Economics, 83, 302-317.

Granger, C. W. J.and Elliot, C. M. (1967). A Fresh look at wheat prices and markets in the Eighteenth Century. Economic History Review, 20, 257-265.

Hansen, B. (2000). Sample splitting and threshold estimation. Econometrica, 68(3): 575-603.

Hansen, B., and Seo, B. (2002). Testing for two-regime threshold cointegration in vector error-correction models. Journal of Econometrics, 110, 293-318.

Kostov, P. and John Lingard (2004). Regime-switching vector error correction model (VECM) analysis of UK meat consumption. Unpublished UCLan Working Paper

Lele, U. (1967). Market integration: a study of sorghum prices in Western India. Journal of Farm Economics, 49, 149-159.

McNew, K. and Fackler, P.L.(1997). Testing market equilibrium: Is cointegration informative? Journal of Agricultural and Resource Economics, 22 (2),191-207.

Meyer, J. (2004). Measuring market integration in the presence of transaction costs - A threshold vector error correction approach. Agricultural Economics, 31, 327-334.

Meyer, J. and von Cramon-Taubadel, S. (2004). Asymmetric price transmission: A survey. Journal of Agricultural Economics 55(3):581-611.

Moschini, G., and K. Meilke (1989). Modeling the pattern of structural change in US meat demand. American Journal of Agricultural Economics, 71, 253-261.

Negassa, A., Myers, R. and E. Gabre-Madhin. (2004). Grain marketing policy changes and spatial efficiency of maize and wheat markets in Ethiopia. Markets, Trade and Institutions Division Discussion Paper No. 66. International Food Policy Research Institute, Washington, D.C. 
Negassa, A., and Myers, R.(2007). Estimating policy effects on spatial market efficiency: An extension to the parity bounds model, American Journal of Agricultural Economics, 89(2), 338-352

Obstfeld, M. and Taylor, A.M. (1997). Nonlinear aspects of goods-market arbitrage and adjustment; Heckscher's commodity points revisited, Journal of the Japanese and International Economies, 11, 441-79.

Ohtani, K., and Katayama, S. (1986). A gradual switching regression model with autocorrelated errors. Economic Letters, 21, 169-172.

Park, A. Hehui, J., Scott, R. and Jikun, H. (2002). Market emergence and transition: arbitrage, transaction costs, and autarky in China's grain markets. American Journal of Agricultural Economics, 84(1), 67-82.

Samuelson, P. (1952). Spatial price equilibrium and linear programming. American Economic Review 42, 283303.

Sephton, P.E. (2003). Spatial market arbitrage and threshold cointegration. American Journal of Agricultural Economics, 85, 1041-1046.

Serra, T., Goodwin, B. K. and Mancuso, A. (2005). Non-parametric Modeling of Spatial Price Relationships. Paper Presented at the 2005 Agricultural Economics Society Annual Conference, Nottingham, UK.

Sexton, R.J., Kling, C.L. and Carman, H.F. (1991). Market integration, efficiency of arbitrage, and imperfect competition: methodology and application to U.S. celery. American Journal of Agricultural Economics 73, 56880 .

Spiller, P.T. and Wood, R.O. (1988). The estimation of transactions costs in arbitrage models, Journal of Econometrics, 39, 309-326.

Takayama, T. and Judge, G. 1971. Spatial and Temporal Price Allocation Models. Amsterdam: North-Holland.

Tsay, R.S. (1989). Testing and modeling threshold autoregressive processes. Journal of the American Statistical Association, 84:231-240.

Tweeten, L.G., and Quance, L. (1969). Positivistic measures of aggregate supply elasticities: some new approaches. American Economic Review, 59, 175-183.

Van Campenhout, B. (2007). Modeling trends in food market integration: Method and application to Tanzanian maize markets. Food Policy 32, 112-127.

Van Campenhout, B. (2009). Sample splitting and threshold estimation techniques. Applications in development studies. Open Access publications from Katholieke Universiteit Leuven urn:hdl:123456789/244590, Katholieke Universiteit Leuven

Von Cramon-Taubadel, S. (1998). Estimating asymmetric price transmission with the error correction representation: an application to the German pork market. European Review of Agricultural Economics, 25, 118.

Received for Publication: 08/02/2012

Accepted for Publication: 24/03/2012 